\title{
Chemoradiation in Unresectable Oral Cavity Cancer: A Myth or Reality!
}

\author{
Vijay Maruti Patil ${ }^{1}$ Vanita Noronha ${ }^{1} \quad$ Amit Joshi $^{1} \quad$ Amit Kumar $^{1}$ Hollis Dsouza ${ }^{1}$ \\ Atanu Bhattacharjee ${ }^{2}$ Abhishek Mahajan ${ }^{1} \quad$ Nilesh Sabale$^{1} \quad$ Sarbani Ghosh-Laskar ${ }^{3} \quad$ Kumar Prabhash $^{1}$ \\ 1Department of Medical Oncology, HBNI, Tata Memorial Hospital, \\ Mumbai, Maharashtra, India \\ 2Department of Epidemiology, Advanced Centre for Treatment, \\ Research and Education in Cancer, Navi Mumbai, Maharashtra, \\ Address for correspondence Kumar Prabhash, DM, Department \\ of Medical Oncology, HBNI, Tata Memorial Hospital, Mumbai, \\ Maharashtra, India (e-mail: kprabhash1@gmail.com).
} India

${ }^{3}$ Department of Radiation Oncology, HBNI, Tata Memorial Hospital, Mumbai, Maharashtra, India

\section{South Asian J Cancer 2021;9:195-198.}



Objective Earlier studies have shown that chemoradiation (CTRT) has benefits in the head-and-neck cancer, but how far it is true for oral cavity subset that has not been exactly explored. Keeping the null hypothesis as CTRT has no benefit in oral cavity cancer, we studied the outcome of patients undergoing chemoradiation in unresectable oral cavity cancers. The aim of this study is to study whether overall survival (OS) increases with chemoradiation in unresectable oral cavity cancers.

Patients and Methods Between December 2014 and February 2017, 23 patients aged 18 years and above were planned chemoradiation for unresectable oral cavity cancer and were included for this analysis.

Results The median age of patients was 43 years and all patients were addicted to tobacco. In total, 12 of 23 (52\%) completed CTRT. One patient (1/23) was alive at the time of final analysis with median OS of 5.83 (2.73-9.60) months. The median progression free survival and OS in patients who completed chemoradiation were 6.42 months (95\% confidence interval $[\mathrm{Cl}]$ : 3.67-10.53) and 8.9 months (95\% Cl: 4.4-23.07), respectively. Conclusion CTRT has a limited role in unresectable oral cancers.

\section{Introduction}

Oral cavity cancer is common in India where people are more habituated to oral chewable forms of tobacco such as khaini, areca nuts, and gutkha. In total, $57 \%$ of all men and $11 \%$ of women between the age of 15 and 49 years use some form of tobacco in India. ${ }^{1}$ The incidence of age-adjusted oral cavity cancer in India is $13.9 / 100,000$ accounting for $11.4 \%$ of all cancer burden. ${ }^{2-4}$ Thus, oral cancer, in particular, continues to be a major problem. Not only it is common, but it is also usually seen in locally advanced stages. Nearly $85 \%$ of oral cancers in India present in this stage. ${ }^{2}$ Locally advanced oral cancers are treated by surgical resection followed by adjuvant therapy. ${ }^{5.6}$ In

\section{DOI https://doi.org/10.1055/s-0041-1728225 ISSN 2278-330X}

How to cite this article: Patil V. M, Noronha V, Joshi A, Kumar A, Dsouza H, Bhattacharjee A, Mahajan A, Sabale N, Ghosh-Laskar S, Prabhash K. Chemoradiation in Unresectable Oral Cavity Cancer: A Myth or Reality!. South Asian J Cancer 2021;9(4):195-198. resectable oral cancers and borderline resectable oral cancer, patients undergoing surgical resection have a survival advantage over patients treated with radical chemoradiation. ${ }^{7-12}$

Oral cancers with the involvement of base of skull or encasement of carotid vessels or involvement of prevertebral fascia or extensive soft tissue involvement precluding negative margins are termed as unresectable. The management of these cancers is a controversy; both palliative therapies and curative-intent treatment are provided as per the institutional policy and patient's general condition. Hence, the treatment of these patients can vary from palliative intent radiotherapy to neoadjuvant chemotherapy followed by radical chemoradiation. We work at a tertiary cancer center and commonly

\section{(c) 2021. MedIntel Services Pvt Ltd.}

This is an open access article published by Thieme under the terms of the Creative Commons Attribution-NonDerivative-NonCommercial-License, permitting copying and reproduction so long as the original work is given appropriate credit. Contents may not be used for commercial purposes, or adapted, remixed, transformed or built upon. (https://creativecommons.org/licenses/by-nc-nd/4.0/).

Thieme Medical and Scientific Publishers Private Ltd A-12, Second Floor, Sector -2, NOIDA -201301, India 
face this dilemma in our multidisciplinary clinic. Hence, we decided to do an audit of unresectable oral cancer patients who were considered for radical chemoradiation at our center.

\section{Patients and Methods}

\section{Selection of Cases}

We maintain a prospective database of patients offered radical chemoradiation at our center. From this database, patients treated between December 2014 and February 2017 were collected subjected to below-mentioned criteria:

- Aged 18 years and above with biopsy-proven squamous cell carcinoma

- Locally advanced unresectable oral cancer:

- The definition of unresectable oral cancer was decided on the basis of multidisciplinary clinic involving the surgical oncologist, radiation oncologist, medical oncologist, radiologist, nuclear medicine expert, pathologist as those involving the prevertebral fascia, encasement of carotid artery, disease extending to base of skull or with extensive soft-tissue involvement or with fixed nodes with encasement of internal or external carotid $>180$ degrees.

- Medical unsuitability for resection was not sufficient for patient eligibility. Similarly, patient refusal of a surgical procedure was not considered a reason for unresectability.

- Who were offered radical chemoradiation

- Eastern Cooperative Oncology Group (ECOG) Performance Stage 0-2

\section{Methods}

The pretreatment staging evaluation included a medical history, physical examination, contrast enhanced computed tomography, and electrocardiogram. The patients and relatives were counseled about the disease and explained the prognosis. After initial evaluation with routine hemogram, biochemistry, and pure tone audiometry, they were offered radical chemoradiotherapy with external beam radiation either through conformal three dimensional or conventional technique at 66 to $70 \mathrm{~Gy}$ given at 1.8 to $2.0 \mathrm{~Gy}$ per fraction 5 days a week along with concurrent cisplatin at $30 \mathrm{mg} / \mathrm{m}^{2}$ weekly with adequate supportive care. Postcompletion of CTRT axial imaging was performed for the response assessment. The patients were followed up at 3 months interval in 1 year and at 4 to 6 months interval from the 2 year onward at the discretion of the physician.

\section{Endpoints}

The primary endpoint of the study was overall survival (OS), which was defined as time duration in months calculated from the date of treatment planning to date of death or last follow-up in patients who do not have an event. The secondary endpoints were treatment compliance and progression free survival. Satisfactory compliance was defined as completion of $95 \%$ of radiotherapy dose or above and six or more cycle of chemotherapy. Progression free survival was defined as time duration in months calculated from the date of treatment planning to date of progression or last follow-up in patients who do not have an event.

\section{Statistical Analysis}

Data were censored for analysis on February 14, 2019. Data were presented with a median (25-75th percentile) for continuous variables and frequency (percentage) for qualitative variables. Survival data were analyzed by using the Kaplan-Meier method and univariate analysis was performed with log-rank test. Median estimates with 95\% confidence interval (CI) (Brookmeyer and Crowley method) were provided.

\section{Results}

\section{Baseline Characteristics}

Baseline patient characteristics are shown in - Table 1. The median age of patients was 43 years ranging from 28 to 68 years. There were 22 males and 1 female. All patients had ECOG performance status $\leq 2$ and were addicted to tobacco. Two patients were hypertensive and one was diabetic. The most common site was buccal mucosa $(n=16 ; 70 \%)$ followed by tongue ( $n=5 ; 22 \%)$. Fourteen patients $(61 \%)$ were Stage IV B and rest were Stage IV A. Bony involvement was present in $13(57 \%)$ patients.

\section{Treatment Planned, Delivered, and Compliance}

The treatment plan was radical chemoradiation in 20 patients (87\%) and neoadjuvant chemotherapy followed by radical chemoradiation in 3 patients (13\%). The treatment compliance with the chemoradiation regimen was $52 \%(n=12)$. The treatment received were CTRT in 11 patients, RT in 1 patient, and 11 patients never started radiation or left it within 1 week. Among patients receiving $>1$ week of treatment, median RT dose was 70 Gy (interquartile range: $60-70)$, and the median number of cisplatin cycles received were $7 .^{5-7}$ Proportion of patients receiving 70 Gy dose and $\geq 200 \mathrm{mg} / \mathrm{m}^{2}$ cisplatin were 8 and 8 , respectively.

\section{Outcomes}

At the data cutoff all patients had progressed and all but one had died. The median progression free survival was 4.40 (95\% CI: 2.07-6.83) months (-Fig. 1) and OS was $5.83(95 \%$

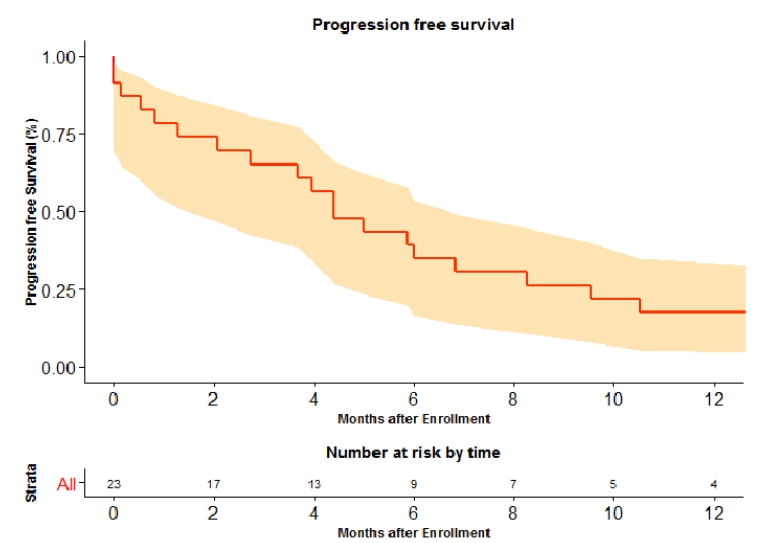

Fig. 1 Progression-free survival curve. 
Table 1 Baseline characteristics $(\mathrm{n}=23)$

\begin{tabular}{|l|l|}
\hline Variable & $\boldsymbol{n}(\%)$ \\
\hline Median age (y) & $43(28-68)$ \\
\hline Gender & \\
\hline Male & $22(95.7)$ \\
\hline Female & $1(4.3)$ \\
\hline ECOG PS & \\
\hline $0-1$ & $22(95.7)$ \\
\hline 2 & $1(4.3)$ \\
\hline Oral tobacco use & $23(100)$ \\
\hline Comorbidity & \\
\hline Hypertension & $2(8.6)$ \\
\hline Diabetes & $1(4.3)$ \\
\hline Site of oral cavity malignancy & \\
\hline Buccal mucosa & $16(69.6)$ \\
\hline Oral tongue & $5(21.7)$ \\
\hline Others & $2(8.7)$ \\
\hline T stage & \\
\hline T4a & $12(52.2)$ \\
\hline T4b & $11(47.8)$ \\
\hline Bone involvement & $13(50.4)$ \\
\hline Yes & $10(43.5)$ \\
\hline No & $5(21.7)$ \\
\hline N stage & $14(60.9)$ \\
\hline N0-1 & $4(17.4)$ \\
\hline N2 & \\
\hline N3 & \\
\hline Stage & \\
\hline IV A & \\
\hline IV B & \\
\hline Reason for unresectability & \\
\hline High ITF or base of skull & \\
\hline Hyoid involvement & \\
\hline Fixed node & \\
\hline
\end{tabular}

Abbreviations: ECOG PS, Eastern Cooperative Oncology Group Performance Stage; ITF, infratemporal fossa.

CI: 2.73-9.60) months (-Fig. 2). In patients who completed CTRT, the median progression free survival 6.42 (95\% CI: 3.67-10.53) months and OS was 8.9 (95\% CI: 4.4-23.07) months, which was significantly better than patients who never took CTRT $(1.03 ; 95 \%$ CI: 0.00-5.87, $p=0.003$; - Fig. 3).

\section{Discussion}

Management of locally advanced oral cavity cancer is multimodality. In clinics, these advanced tumors are commonly broken as resectable, borderline resectable, and unresectable. Surgery followed by adjuvant treatment remains the cornerstone and the preferred modality of choice in resectable oral cancers. As the 5-year disease-specific survival rates

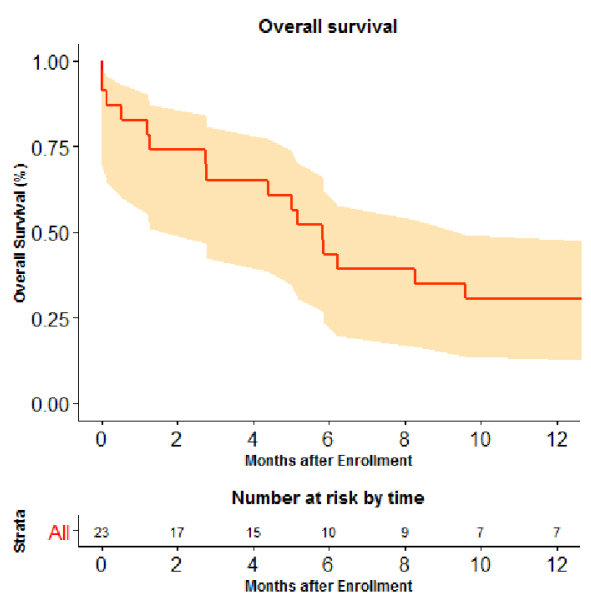

Fig. 2 Overall survival curve.

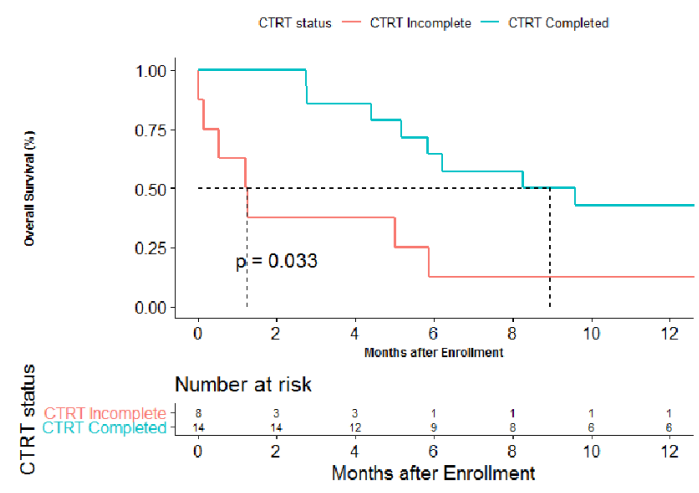

Fig. 3 Overall survival according to chemoradiation status.

are $68 \%$ for surgery versus $12 \%$ for the chemoradiation arm $(p=0.038) .{ }^{12}$ However, in borderline resectable or unresectable tumors, upfront surgery is not an option. Curative high-dose radiation with chemotherapy is one of the options of treatment in such settings. However, our results clarify the dismal results of CTRT in such patients.

The patient with unresectable disease is offered chemoradiation as a routine practice based on data from the role of chemoradiation in the head-and-neck cancer without subsite specifications. ${ }^{12}$ In our study, the outcome of patients with unresectable oral cavity cancers which included patients with bony involvement and high nodal status chemoradiation was not improved with respect to historical outcomes with palliative systemic therapy. The outcome of oral cavity cancer has improved in the modern era with better supportive care, but still unresectable disease is an unmet need with no effective treatment modality. These patients should be offered instead experimental therapy in clinical trials setting.

We searched PubMed for clinical studies published in English between January 1, 1980 and February 14, 2019, with the MeSH terms "oral cancer" and "unresectable" with filters applied for "reviews." Eight hundred and thirty-seven studies were screened. We identified nine relevant publications. They showed a response to chemoradiation and chemotherapy followed by chemoradiation. However, none were restricted to the oral cavity except 
two publications. Nair et al from Regional Cancer Centre Trivandrum in $1988^{13}$ showed role of radiation in buccal mucosa cancer; disease-free survival at 3 years for Stage IV disease was $15 \%$. These results look much more promising than our results; however, a closer look at the study methodology suggests that these patients were very carefully selected. In this study, only those lesions who could be treated with a single lateral field, the size ranging from 8 $\times 8 \mathrm{~cm}$ to $10 \times 10 \mathrm{~cm}$ were included. The field size allowed covering of only primary and the first-echelon lymph nodes were included. It means that only small 3 to $5 \mathrm{~cm}$ disease with N0 or N1 status only were included in the study. In this study, all patients had large T sizes, with half being T4b. In addition, $78 \%$ of patients were $\mathrm{N} 2$ and $\mathrm{N} 3$ nodal disease. The results of Nair et al seem to be more eligible for advanced resectable buccal cancers and not for advanced unresectable oral cancers like seen in our study. This is testified by similarity of its results with the results obtained with CTRT from Singapore. ${ }^{12}$ In a report by Stenson et al, ${ }^{14}$ advanced oral cavity cancer had a 5 -year OS of $66.9 \%$ with chemoradiation. These results also are obtained in a select group of patients, nearly $40 \%$ of the patients having T stage T3 or below, suggesting again that these results are applicable to resectable oral cancers and not to advanced unresectable oral cancers as seen in our series.

The compliance with treatment in our study was poor. This is mainly because of the inability of CTRT to provide immediate relief to these patients with very advanced tumors and hence patients opting out of it. CTRT in such advanced tumors is difficult to deliver due to the high gross tumor volume, thus leading to high clinical target volumes. The anatomical proximity to vital structures and mandibular bone make it difficult to administer tumoricidal doses. Similar high noncompliance with treatment is shown in a study by Cheraghlou et al, ${ }^{15}$ where oral cavity cancer patients who had the advanced disease were more likely to go untreated. However, survival among untreated patients is poor, and some form of palliative treatment should be offered in such patients.

The limitation of our study was retrospective design, single-arm and high rate of noncompliance. However, still it matches with community compliance rate. The strength of the study lies in its homogeneous population with strictly defined criteria, uniform treatment for all, and follow-up.

\section{Conclusion}

The natural course of unresectable oral cavity cancer carries a poor prognosis, and chemoradiation is unable to alter it.

\section{Funding}

N. reports research grants from Dr. Reddy's Laboratories Inc, Amgen, Sanofi India Ltd., Intas Pharmaceuticals and Astra Zeneca Pharma India Ltd., outside the submitted work. K.P. reports grants from Biocon Ltd, grants from Dr. Reddy's Laboratories Inc, grants from Fresenius Kabi India Pvt Ltd, grants from Alkem Laboratories, grants from Natco Pharma Ltd, grants from BDR Pharmaceuticals Intl Pvt Ltd, grants from Roche Holding AG, outside the submitted work. All grants were paid to the institution.

\section{Conflict of Interest}

Dr. Noronha reports research grants from Dr. Reddy's Laboratories Inc, Amgen, Sanofi India Ltd., Intas Pharmaceuticals and Astra Zeneca Pharma India Ltd., outside the submitted work.

Dr. Prabhash reports grants from Biocon Ltd, grants from Dr. Reddy's Laboratories Inc, grants from Fresenius Kabi India Pvt Ltd, grants from Alkem Laboratories, grants from Natco Pharma Ltd, grants from BDR Pharmaceuticals Intl Pvt Ltd, grants from Roche Holding AG, outside the submitted work. All grants were paid to the institution.

None of the other authors have anything to declare that may be considered as potential competing interests.

\section{References}

1 Kekatpure V, Kuriakose MA. Oral Cancer in India: Learning from Different Populations. Cancer Prevention; 2010

2 Sankaranarayanan R, Ramadas K, Thomas G, et al. Trivandrum Oral Cancer Screening Study Group. Effect of screening on oral cancer mortality in Kerala, India: a cluster-randomised controlled trial. Lancet 2005;365(9475) :1927-1933

3 GLOBOCAN. The Global Cancer Observatory. GLOBOCAN. Available at: https://gco.iarc.fr/. Accessed 2018

4 Bray F, Ren JS, Masuyer E, Ferlay J. Global estimates of cancer prevalence for 27 sites in the adult population in 2008. Int J Cancer 2013;132(5):1133-1145

5 NCCN. Guidelines Version 2. Available at: https://www.nccn. org/professionals/physician_gls/default.aspx. Accessed 2018

6 Grégoire V, Lefebvre JL, Licitra L, Felip E. On behalf of the EHNS-ESMO-ESTRO guidelines working group. Squamous cell carcinoma of the head and neck: EHNS-ESMO-ESTRO Clinical practice guidelines for diagnosis, treatment and follow-up. Ann Oncol 2010;21:184-186

7 Patil VM, Prabhash K, Noronha V, et al. Neoadjuvant chemotherapy followed by surgery in very locally advanced technically unresectable oral cavity cancers. Oral Oncol 2014;50(10): 1000-1004

8 Joshi A, Patil VM, Noronha V, et al. Is there a role of induction chemotherapy followed by resection in T4b oral cavity cancers? Indian J Cancer 2013;50(4):349-355

9 Patil VM, Kane S, Noronha V, et al. NACT in locally advanced oral cancers: does HPV make a difference? J Clin Oncol 2015 33(Suppl 15) :e17068-e8

10 Noronha V, Patil VM, Joshi A, et al. Induction chemotherapy in technically unresectable locally advanced carcinoma of maxillary sinus. Chemother Res Pract 2014;2014:487872

11 Patil VM, Noronha V, Joshi A, et al. Induction chemotherapy in technically unresectable locally advanced oral cavity cancers: does it make a difference? Indian J Cancer 2013;50(1):1-8

12 Iyer NG, Tan DS, Tan VK, et al. Randomized trial comparing surgery and adjuvant radiotherapy versus concurrent chemoradiotherapy in patients with advanced, nonmetastatic squamous cell carcinoma of the head and neck: 10-year update and subset analysis. Cancer 2015;121(10):1599-1607

13 Nair MK, Sankaranarayanan R, Padmanabhan TK. Evaluation of the role of radiotherapy in the management of carcinoma of the buccal mucosa. Cancer 1988;61(7):1326-1331

14 Stenson KM, Kunnavakkam R, Cohen EE, et al. Chemoradiation for patients with advanced oral cavity cancer. Laryngoscope 2010;120(1):93-99

15 Cheraghlou S, Kuo P, Mehra S, Yarbrough WG, Judson BL. Untreated oral cavity cancer: long-term survival and factors associated with treatment refusal. Laryngoscope 2018;128(3): 664-669 